\title{
Somatosensory evoked potential monitoring
}

\section{Georgene Singh}

\section{INTRODUCTION}

The somatosensory evoked potential (SSEP) monitoring is the electrophysiological response of the nervous system to sensory stimulation. ${ }^{[1]}$ The peripheral mixed nerves are stimulated electrically, and the response is measured along the sensory pathway. SSEP reflects the functional integrity of the somatosensory pathways. They not only reflect specific sensory transmission but also serve as more general indicators of neurological function in adjacent structures.

\section{HOW IS A SOMATOSENSORY EVOKED POTENTIAL GENERATED?}

SSEPs are elicited by mechanical or thermal stimulation of somatic sensory nerves. The most common stimulus used is an electrical pulse. It is delivered to a peripheral nerve which is a large mixed motor and sensory nerves such as median nerve, ulnar nerve and common peroneal or posterior tibial nerve.

The peripheral nerve stimulation activates the large diameter fast conducting Ia muscle afferent and Group II cutaneous nerve fibres. This produces a neural transmission which proceeds both in the normal direction (orthodromic) and in the reverse direction (antidromic). The orthodromic motor stimulation elicits a muscle response which is seen as a twitch and confirms stimulation. The orthodromic sensory stimulation produces the SSEP. The incoming volley of neural activity from stimulation represents primarily the pathway of proprioception and vibration that ascends the ipsilateral dorsal column synapsing in the dorsal column nuclei, nucleus cuneatus and

Associate Professor, Department of Anaesthesiology, Christian Medical College, Vellore, Tamil Nadu, India

\begin{tabular}{|l|l|}
\hline \multicolumn{2}{|c|}{ Access this article online } \\
\hline Quick Response Code: & Website: \\
\hline & www.jnaccjournal.org \\
\cline { 2 - 3 } & \\
\hline
\end{tabular}

gracilis (first order fibres). It then decussates near the cervicomedullary junction ascending via the contralateral medial lemniscus (second order fibres). A second synapse occurs in the ventro-posterolateral nucleus of the thalamus. The third order fibres from the thalamus project to the frontoparietal sensory motor cortex..$^{[2]}$

\section{SENSORY PATHWAY}

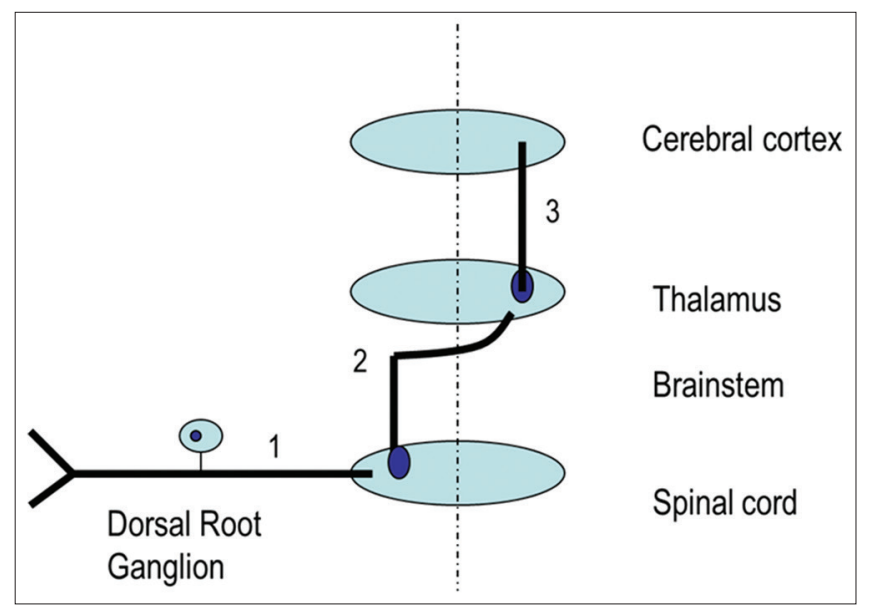

The waveform resulting from the stimulation of a nerve is displayed as a plot of voltage against time and is characterised by measurements of post-stimulus latencies (in milliseconds) and amplitudes (in microvolts) of particular peaks. According to convention, deflections below the baseline are labelled positive $(\mathrm{P})$ and those above the baseline are negative $(N)$. Standard identification of waveforms is by a letter designating the direction of the deflection followed by a number representing the latency of the waveform.

This is an open access article distributed under the terms of the Creative Commons Attribution-NonCommercial-ShareAlike 3.0 License, which allows others to remix, tweak, and build upon the work non-commercially, as long as the author is credited and the new creations are licensed under the identical terms.

For reprints contact: reprints@medknow.com

How to cite this article: Singh G. Somatosensory evoked potential monitoring. J Neuroanaesthesiol Crit Care 2016;3:97-104. 


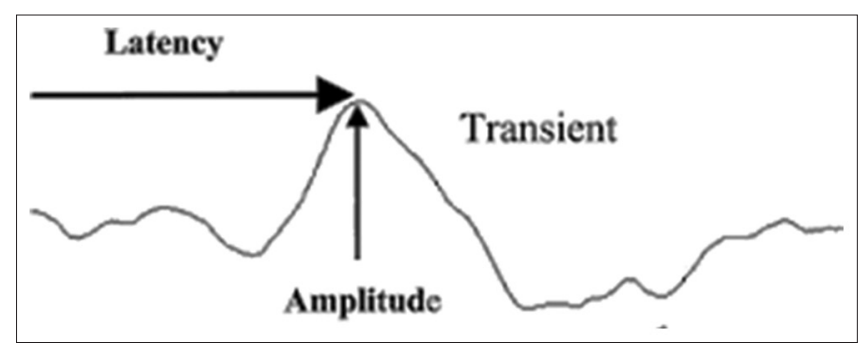

POST-STIMULUS LATENCY

The post-stimulus latency of an SSEP peak reflects the time required for impulse transmission from the site of sensory stimulation to the neurophysiological generator of that peak. Thus, the latency depends on the length of the sensory pathway and the speed of neural conduction.

Two measurements derived from the post-stimulus latencies are used to help characterise neurological function, conduction velocity (CV) and central conduction time $(\mathrm{CCT})$.

$\mathrm{CV}$ can be estimated from the post-stimulus latency of evoked electrical activity and the distance from the stimulus site to the recording electrode.

CCT is calculated by measuring the intervals between the peaks and reflects pathophysiological alterations in brain function..$^{[1]}$

\begin{tabular}{|c|c|c|}
\hline \multicolumn{3}{|c|}{$\begin{array}{l}\text { Generators of the somatosensory evoked potentials } \\
\text { after median nerve stimulation }{ }^{[3]}\end{array}$} \\
\hline Peak & Generator & Recording site \\
\hline N9 & Brachial plexus & Erb's point \\
\hline N11 & Posterior columns & Cervical \\
\hline N13/P13 & $\begin{array}{l}\text { Dorsal column } \\
\text { nucleus cuneatus }\end{array}$ & Cervical \\
\hline N14, 15 & $\begin{array}{l}\text { Medial lemniscus } \\
\text { (brainstem) }\end{array}$ & $\begin{array}{l}\text { Cervicomedullary } \\
\text { junction }\end{array}$ \\
\hline $\mathrm{N} 18,22$ & Parietal sensory cortex & Scalp \\
\hline N20 & Somatosensory cortex & Scalp \\
\hline
\end{tabular}



\begin{tabular}{lll}
\hline \multicolumn{2}{c}{$\begin{array}{c}\text { Generators of somatosensory evoked potential } \\
\text { after tibial nerve stimulation }\end{array}$} \\
\hline Peak & Generator & Recording site \\
\hline N20 & Spinal root/cord & Lumbar \\
P27 & Nucleus gracilis & Cervical spine \\
N35 & Somatosensory cortex & Scalp \\
P40 & Somatosensory cortex & Scalp \\
\hline
\end{tabular}

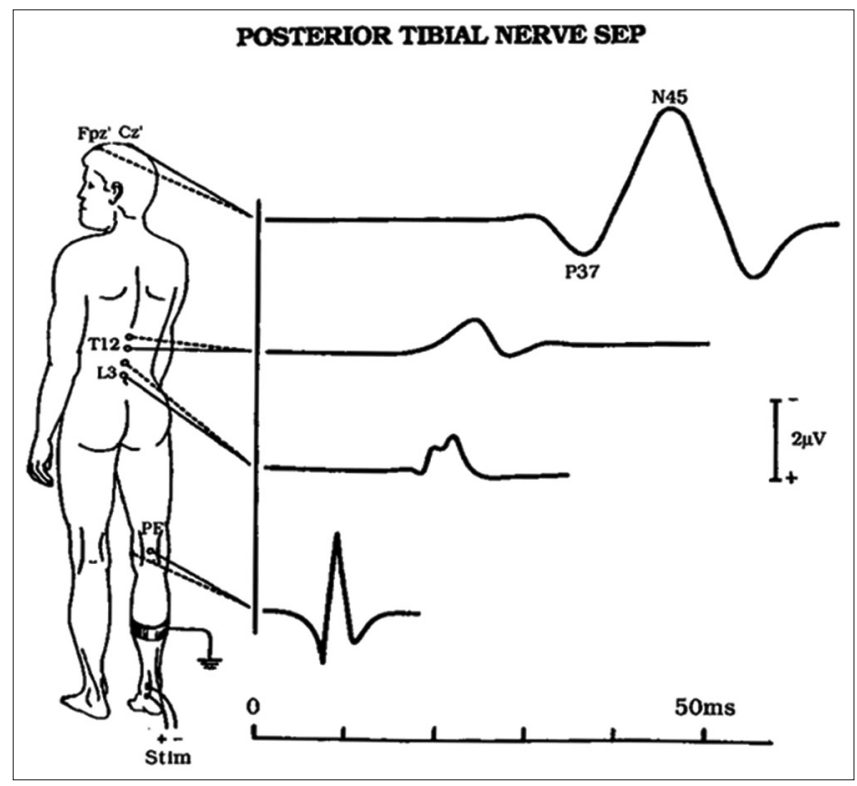

SSEPs consist of both short- (<40 ms) and long- ( $>120 \mathrm{~ms})$ latency evoked potentials. The primary cortical evoked responses result from the earliest electrical activity generated by the cortical neurons. They arise from the post-central sulcus parietal neurons. These are the short latency SSEPs that are most commonly studied intraoperatively because they are less influenced by anaesthetic factors.

The secondary cortical potentials which are of longer latency arise in the association cortex and are less stable and have greater variability of waveform and are extremely difficult to record in the operating room environment. ${ }^{[4]}$

SSEP responses from the upper extremity primarily represent activity in the posterior column pathway whereas those from the lower extremity also include additional components that pass in the spinocerebellar pathway.

\section{RECORDING OF SOMATOSENSORY EVOKED POTENTIAL}

The mode of stimulation is either the median nerve at the wrist or the tibial nerve at the ankle. The peripheral nerve is stimulated at a rate of $2-4 \mathrm{~Hz}$ with 
the duration of $0.2-2$ ms depending on the type of surgery. A sufficient number of repetitions must be averaged to produce an interpretable SSEP. Generally, 100-500 repetitions are needed. The filters settings should be kept constant during the procedure and usually it lies in between 10 and $1000 \mathrm{~Hz}$. The analysis time for median nerve is $50 \mathrm{~ms}$ and for tibial nerve is $100 \mathrm{~ms}^{\left[{ }^{[5]}\right.}$

For the upper extremity, the evoked responses can be measured from electrodes placed over the antecubital fossa, supraclavicular fossa (brachial plexus), cervical spine and cortex. For the lower extremity, they can be recorded over the popliteal fossa, along the spinal cord (surface or epidural electrodes) and at cervical and cortical locations. Response recordings are usually recorded at multiple recording sites, to verify that the nervous system is stimulated and to identify the location of neural compromise if the response is lost.

The cortical response is best recorded over the primary somatosensory cortex appropriate for the nerve which is stimulated. Recording electrodes are placed on the scalp at $\mathrm{C}^{\prime}$ ' or $\mathrm{C}^{\prime}$ for median nerve and $\mathrm{Cz}^{\prime}$ or $\mathrm{Cz}^{\prime \prime}$ for tibial nerve. The reference electrode is placed at Fpz. The measuring peak latencies for median nerve are N20, P25 and for tibial nerve are P37, N45.

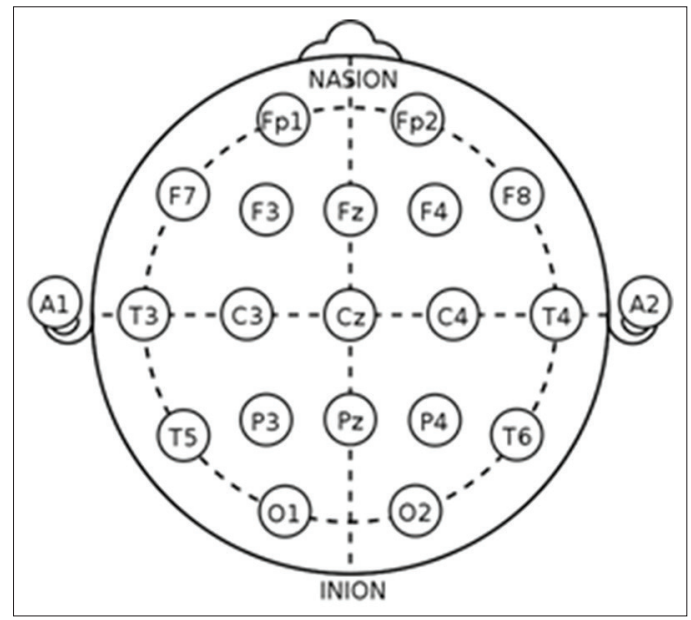

International 10-20 system for electroencephalogram

It is helpful to record both brainstem and cortical SSEP signals because though each can serve as a monitor of dorsal column function, anaesthetic agents and electrical interference in the operating room affect the two classes of signals differently. Cortical SSEPs are relatively resistant to muscle noise and electrical artefact but can be suppressed by anaesthetic agents. Brainstem SSEPs are much more susceptible to electrical noise and electromyographic (EMG) artefacts but are largely unaffected by anaesthetic drugs. Thus, both cortical and brainstem SSEPs complement each other.

\section{RECORDING ELECTRODES}

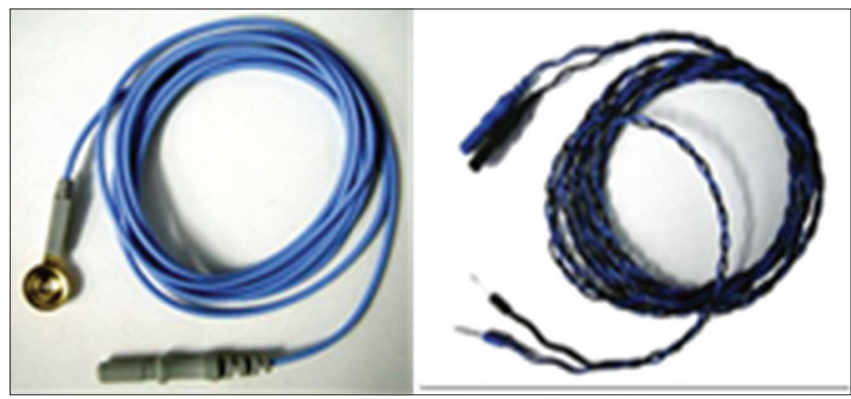

Either standard disc electroencephalogram (EEG) electrodes or $12 \mathrm{~mm}$ twisted pair sub-dermal platinum-iridium tip needle electrodes of 27-gauge are commonly used. Skin preparation and the proper electrode placement are important. Either surgical spirit or NuPrep Gel (Viasys Healthcare, US) is used. Electrodes need to be secured well or they may come off during the procedure. ${ }^{[5]}$

\section{STIMULATION}

When the median nerve is stimulated for SSEP monitoring, the cathode should be placed between the tendons of the palmaris longus and the flexor carpi radialis muscles, $2 \mathrm{~cm}$ proximal to the wrist crease. The anode should be placed $2-3 \mathrm{~cm}$ distal to the cathode or on the dorsal surface of the wrist. For stimulation of the tibial nerve, the cathode should be placed over the posterior portion of the medial surface of the ankle, $1-2 \mathrm{~cm}$ distal and posterior to the medial malleolus. The anode should be placed $2-3 \mathrm{~cm}$ distal to the cathode. Gold-plated stainless steel disc electrodes with $9 \mathrm{~mm}$ diameters and $30 \mathrm{~mm}$ spacing are used for stimulation.

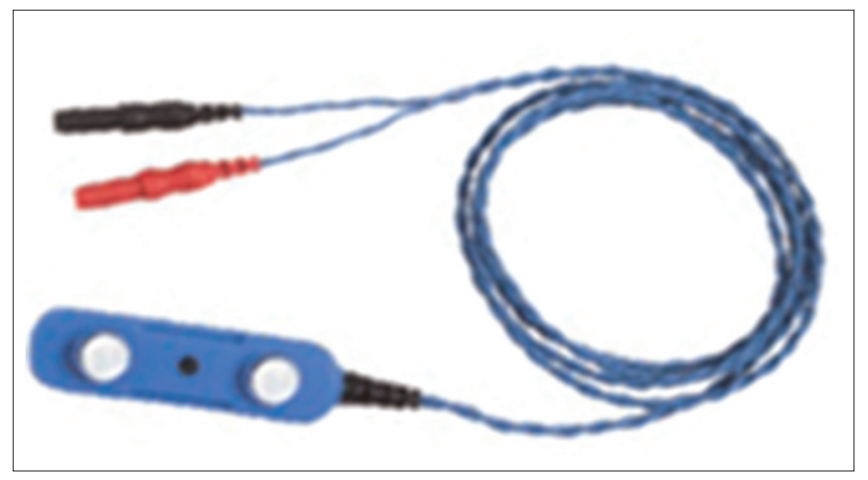

\section{CRITERIA FOR SIGNIFICANT CHANGE IN SOMATOSENSORY EVOKED POTENTIAL}

A $50 \%$ decrease in the amplitude and a $10 \%$ increase in latency from the baseline is associated with injury to the 
large fibre dorsal column pathways. ${ }^{[6]}$ SSEP responses being very low in amplitude require prolonged averaging. Therefore, it may take 3-5 min to determine a significant change depending on the ambient noise level.

In intraoperative spinal cord injury, loss of SSEP amplitude and degradation of the signal morphology are commonly noticed due to conduction block and desynchronisation. The changes in latencies are less prominent. Ignoring an amplitude change in the event of normal latencies can therefore be disastrous. Moreover, $50 \%$ decrease in the amplitude and a 10\% increase in latency alarm criteria is empirically based and are best used as a guide rather than a strict threshold above which it can be assumed that no adverse effect can happen. It is therefore prudent to inform even small changes in the SSEP that exceed the prior variability. This will facilitate more accurate identification of the cause and alerts the surgeon who will decide to either act or wait and observe.

The use of amplitude criteria is associated with better sensitivity for detecting neurologic injury than latency criteria. The SSEPs have high specificity and low sensitivity to injury. ${ }^{[7]}$

\section{OPTIMAL CONDITIONS FOR SOMATOSENSORY EVOKED POTENTIAL MONITORING}

An anaesthetic technique that does not markedly depress the cortical SSEP recording should be used. The anaesthetic depth and physiological state of the patient should remain as constant as possible during critical periods of monitoring when there can be potential surgical injury to the monitored pathway such as during carotid clamping, aneurysm clipping or induced hypotension. Major changes in the anaesthetic gas levels and boluses of intravenous anaesthetics should be avoided during critical periods. Reliable baseline tracings should be obtained during any intervention. Electrical interference due to cautery etc., should be reduced. ${ }^{[8]}$

\section{ANAESTHETIC FACTORS WHICH ALTER THE SOMATOSENSORY EVOKED POTENTIAL RECORDING}

Since anaesthetic agents depress the synaptic function, the more synapses in the monitored neurological pathway, the more marked the effect on latency and amplitude of SSEPs. SSEPs are affected by altered synaptic function, altered ancillary neural pathways which suppress or enhance the primary monitored pathway, global effect of anaesthetics on cortical and spinal cord neural processing. ${ }^{[9]}$

\section{EFFECTS OF SPECIFIC ANAESTHETIC AGENTS ON SOMATOSENSORY EVOKED POTENTIAL}

\section{Inhalational anaesthetic agents}

Halogenated volatile anaesthetics are shown to reduce SSEP amplitude and prolong their latencies. Isoflurane has the most potent effect and halothane the least. Sevoflurane and desflurane are less soluble, and hence the anaesthetic effects on SSEP changes, rapidly when their concentrations are changed making them ideal for monitoring. ${ }^{[10]}$

\section{Nitrous oxide}

Nitrous oxide (60-70\%) decreases the cortical amplitude by about $50 \%$ but does not alter the cortical latency and sub-cortical waveform. This is because of its potent effect on neuronal nicotinic acetylcholine receptors. Hence, it is prudent to avoid nitrous oxide. ${ }^{[9]}$

\section{Propofol}

At high doses, it decreases the amplitude and prolongs the latency but its combined use with other sedative-analgesic agents allows for the use of lower concentrations which preserve evoked potential. Because of its rapid metabolism, it allows easy titration which makes it an anaesthetic of choice in SSEP monitoring. ${ }^{[9,10]}$

\section{Thiopentone sodium}

A transient decreased amplitude and increased latency of evoked potentials are observed after induction with thiopentone. The effect lasts $<10 \mathrm{~min} \cdot{ }^{[27]}$ Minimal effects are seen on sub-cortical and peripheral responses. It influences synaptic transmission more than axonal conduction. ${ }^{[10]}$

\section{Etomidate}

Etomidate causes an increase in the amplitude of cortical SSEPs. After a bolus, there is prolongation of the latency and CCT. However, etomidate infusions have been used to enhance SSEP recording in patients in whom it was not possible to obtain reliable recordings due to pathologic findings. ${ }^{[10]}$

\section{Ketamine}

Although ketamine increases the cortical SSEP amplitude, it can increase intracranial pressure (ICP) in patients with cortical abnormalities and thus affect the SSEP. It has minimal effects on sub-cortical and peripheral SSEP responses. ${ }^{[10]}$ 


\section{Midazolam}

Midazolam causes mild suppression of cortical SSEPs at doses used for induction of anaesthesia $(0.2 \mathrm{mg} / \mathrm{kg}) .^{[10]}$

\section{Dexmedetomidine}

At low doses, SSEPs are preserved but these are suppressed at higher doses. It is best used in combination with other agents to decrease the doses of total intravenous anaesthesia. ${ }^{[9]}$

\section{Opioids}

The latencies are preserved at high doses. However, there is a dose-dependent decrease in amplitude. Even at high doses $(60 \mathrm{mcg} / \mathrm{kg})$ the use of fentanyl results in reproducible SSEPs making it an ideal agent during SSEP recordings. Morphine causes dose-dependent suppression of SSEPs. Pethidine increases the amplitude of SSEPs. Although remifentanil has a dose-dependent effect on evoked potentials, its rapid metabolism allows for titration. ${ }^{[4]}$

\section{Muscle relaxants}

SSEPs are unaffected by muscle relaxants since SSEPs do not arise from muscle activity. The use of neuromuscular antagonists may improve the quality of recording by reducing EMG interference near the recording electrodes. ${ }^{[10]}$

\section{PHYSIOLOGICAL FACTORS AFFECTING SOMATOSENSORY EVOKED POTENTIAL}

\section{Blood flow and blood pressure}

The amplitude of cortical SSEPs decreases when the regional cerebral blood flow falls below $20 \mathrm{ml} / \mathrm{min} / 100 \mathrm{~g}$ and is completely lost below $15 \mathrm{ml} / \mathrm{min} / 100 \mathrm{~g}$. SSEPs are more sensitive to hypoperfusion. Even an acceptable blood pressure at the lower limit of normal autoregulation may cause a decline in SSEPs. Further, SSEPs may be decreased by the local pressure effects due to retraction, positioning. ${ }^{[11]}$

Sub-cortical regions, such as the brainstem, spinal cord and nerve, appear to be less sensitive to hypoperfusion. Hence, SSEP persists at blood pressures below which the EEG routinely disappears.

\section{Haematocrit}

Decreased oxygen delivery associated with anaemia during isovolemic haemodilution results in progressives in the latencies of SSEP which is marked at haematocrit $<15 \%$. At very low haematocrits, amplitude of all waveforms is decreased. ${ }^{[10]}$

\section{Temperature}

Hypothermia causes an increase in latency and decrease in amplitude. With increase in temperature, there are decreases in amplitudes and loss of SSEP at $42^{\circ} .{ }^{[10]}$

\section{Hypoxia}

Hypoxia leads to decreased amplitude similar to ischaemia.

\section{Increased intracranial pressure}

Because of the pressure-related effects on cortical structures, reduced amplitudes and increased latencies are noticed with elevation in ICP. ${ }^{[10]}$

\section{Ventilation}

The vasoconstrictive effects of hypercapnoea may modify spinal and cortical blood flow which may alter SSEP at $\mathrm{PaCO}_{2}<20 \mathrm{mmHg} \cdot{ }^{[10]}$

Changes in the neurochemical milieu also affect SSEPs. Blood glucose levels and electrolytes should be monitored and kept within normal limits.

\section{WHEN DO WE MONITOR SOMATOSENSORY EVOKED POTENTIAL?}

To achieve maximal benefit from intraoperative SSEP monitoring, it is important to ascertain that the neural structures/pathways which are potentially at risk are amenable to reliable monitoring. There must be an option for either surgical or anaesthetic intervention should there be a suspected dysfunction or trespass of the pathway so that it minimises the chances of permanent damage. It should provide information about the nervous system under anaesthesia as would be obtained by clinical examination of conscious patients. SSEPs are monitored only if the site of stimulation and recording are accessible during surgery and reliable equipment and neurophysiologist are available for accurate interpretation of recorded signals. ${ }^{[1]}$

\section{SURGICAL PROCEDURES MONITORED WITH SOMATOSENSORY EVOKED POTENTIAL}

\section{Surgeries of the spine}

- Correction of scoliosis with instrumentation ${ }^{[12]}$

- Spinal cord decompression and stabilisation after acute spinal cord injury ${ }^{[13]}$

- Spinal fusion ${ }^{[14]}$

- Release of tethered cord ${ }^{[15]}$

- Resection of spinal cord tumour/cyst/vascular lesion $^{[15]}$

- Correction of cervical spondylosis. ${ }^{[15]}$

Surgeries of the brain

- Localisation of the sensorimotor cortex ${ }^{[15]}$

- Clipping of intracranial aneurysms ${ }^{[16]}$

- Resection of intracranial vascular lesions involving the sensory cortex and arteriovenous malformation ${ }^{[17]}$

- Resection of thalamic tumour

- Brainstem surgeries. 


\section{Vascular surgery}

- Carotid endarterectomy $(\mathrm{CEA})^{[18]}$

- Abdominal and thoracic aortic aneurysm repair ${ }^{[19]}$

- Repair of coarctation of the aorta. ${ }^{[20]}$

\section{Intensive Care Unit}

- Prognosticationinhypoxic-ischaemicencephalopathy/ traumatic brain injury (TBI) ${ }^{[23]}$

- Acute neurological deteriorations.

Others

- Brachial plexus exploration after injury ${ }^{[20]}$

- Positioning during surgeries of the skull base ${ }^{[21]}$

- Chronic pain ${ }^{[22]}$

- Herpetic neuralgia. ${ }^{[4]}$

\section{LOCALISATION OF THE SENSORIMOTOR CORTEX}

Precise localisation of the motor cortex is important to minimise the risk of contralateral motor deficits resulting from the surgical procedures which occur in close proximity to the motor cortex. Very often, the anatomical and radiological landmarks of sensorimotor cortex are distorted by the pathological lesion. The signal of SSEPs after stimulation of the contralateral median/tibial nerve is recorded from a sub-dural strip electrode placed on the sensorimotor cortex across the central sulcus. High-amplitude potentials are recorded from the electrodes lying on the post-central gyrus corresponding to N20/P40. Inverted potentials (potentials which are mirror images of each other) are recorded from the electrodes positioned on the primary motor cortex. The central sulcus is then neurophysiologically identified between the two electrodes which show the phase reversal (inversion of post-central negative and pre-central positive peak) of the SSEPs. A phase reversal across central sulcus is a highly reproducible characteristic that helps in the localisation of the primary motor cortex. ${ }^{[15]}$

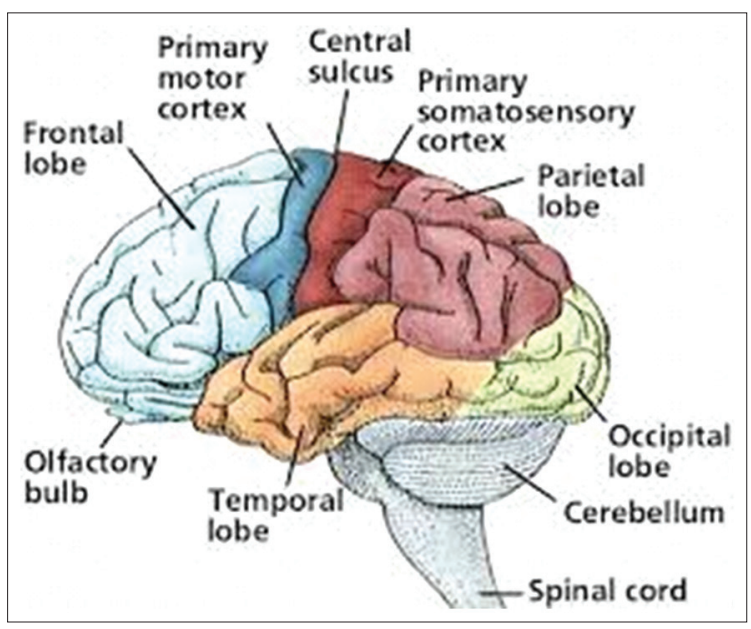



\section{SURGERIES OF THE SPINE}

The earliest form of electrophysiological monitoring for scoliosis surgery was SSEP monitoring. A survey of the scoliosis research society and the European spinal disorder society showed that there was a decrease in injury from $0.7 \%$ to $4 \%$ in the pre-SSEP era to $<0.55 \%$ with SSEP monitoring. ${ }^{[7]}$

However, some patients had SSEP monitoring that failed to detect significant spinal cord injury. The primary conduction pathway of the SSEP in the spinal cord is the dorsal column. The blood supply of the dorsal column is different from that of the anterior two-third of the spinal cord which derives its blood supply from the anterior spinal artery. Loss of blood flow through the anterior spinal artery would place the anterior two-third of the spinal cord at risk while the dorsal column remains intact. Hence, it is advisable to monitor both SSEP and motor evoked potential.

The level of surgery determines the choice of stimulation and the recording sites. If the surgical site is the cervical spine, median nerve SSEP is monitored and if the SSEP is below the cervical level, tibial SSEPs are monitored. Recording over a popliteal or supraclavicular space provides a control.

\section{ANEURYSM SURGERY}

Median nerve SSEP is generated by the primary somatosensory cortex which sub-serves the arm and receives blood supply from the middle cerebral artery (MCA). Hence, it is useful to monitor the ischaemic insult associated with cerebral aneurysm surgery, especially during temporary occlusion of the MCA/internal carotid artery. Similarly, tibial nerve SSEP has been used to monitor ischaemic events associated with anterior cerebral artery aneurysm. Thalamic 
sub-cortical activity supplied by the posterior cerebral artery can also be monitored using median nerve SSEPs. The rationale for employing SSEP is the strong correlation between electrophysiological changes and regional cerebral blood flow. Ischaemia also prolongs the CCT. ${ }^{[16]}$

The CCT of more than 9-10 ms correlates with the neurological deficits whereas that below $10 \mathrm{~ms}$ was associated with good outcome. Posterior circulation aneurysms require dual monitoring with SSEP and brainstem auditory evoked potentials. ${ }^{[24]}$

Monitoring during temporary clipping in aneurysm surgery has shown that a very prompt loss of cortical SSEP response ( $<1 \mathrm{~min}$ after clipping) is associated with development of permanent neurological deficit. However, a delayed loss with prompt recovery after the release of the clip is associated with the presence of collateral circulation with a markedly reduced incidence of neurological morbidity. When the N20 of the median nerve disappears slowly, 10 more minutes of occlusion may be tolerated safely. Thus, SSEPs help us to guide in determining the duration of temporary clipping. ${ }^{[2]}$

SSEP monitoring can also be used to:

- Identify ischaemia from vasospasm

- Unexpectedischaemia(retractorpressure,hypotension, temporary clipping and hyperventilation)

- Monitoring during neuroradiology procedures

- Streptokinase dissolution of blood clots.

\section{Carotid endarterectomy}

Intraoperative SSEP changes are used as an indicator for shunt placement and to predict post-operative morbidity. SSEP and EEG in CEA are complementary. Since SSEP is able to detect ischaemia in the deep cortical structures, EEG assesses a wider area of the surface cortex. ${ }^{[25]}$

\section{Aortic aneurysm}

Reversible changes in SSEP were not significantly associated with immediate neurological deficit whereas irreversible changes in SSEP are associated with significant neurological deficit. ${ }^{[19]}$

\section{Positioning}

Upper extremity stress during positioning has been detected in real time using SSEP in patients undergoing skull base surgery. ${ }^{[21]}$

\section{Chronic pain}

In chronic pain, Kumar et al. observed that the absolute peak latency of N19 is significantly delayed in chronic pain patients suffering from musculoskeletal disorders. ${ }^{[22]}$ Mahajan et al. have shown that a delay in CCT is observed in those with herpetic neuralgia. ${ }^{[4]}$

\section{ROLE OF SOMATOSENSORY EVOKED POTENTIAL IN THE INTENSIVE CARE UNIT}

Clinical neurophysiology plays a vital role in the diagnosis, prognosis and monitoring in the Intensive Care Unit (ICU). EEGs and SSEPs are the most informative neurophysiological tests in the ICU. EEG is highly variable and sensitive to neurosedation whereas SSEPS are resistant to sedation and metabolic derangement and have waveforms that are easily interpretable and comparable. However, SSEPs are sensitive to structural hypoxic/ischaemic damage. Bilateral absence of cortical SSEPs recorded on the day 1 following cardiac arrest accurately predicts poor outcome. Since SSEP amplitudes do not decrease during mild hypothermia $\left(34-32^{\circ} \mathrm{C}\right)$, it can be used in prognostication even in the cases of therapeutic hypothermia. In coma induced by TBI, the SSEPs are able to predict both the poor and the favourable prognosis. Continuous SSEP monitoring is able to detect neurological deterioration in acute brain injury. Prolongation of the CCT in comatose patients has been associated with worse long-term prognosis. The CCT is the difference between the latencies of the responses recorded over the cervical spine and that recorded over the sensory cortex. In subarachnoid haemorrhage, prolongation of the CCT is associated with transient neurological deficit and it precedes the development of these deficits. The changes in CCT are related to cerebral ischaemia. ${ }^{[23]}$

In summary, intraoperative monitoring of SSEPs have many valuable application. Correlation between intraoperative SSEP and post-operative functions are good. The scoliosis research society has developed a position statement that 'neurophysiological monitoring can assist in the early detection of complications and possibly prevent post-operative morbidity in patients undergoing surgery on the spine ${ }^{\prime} .{ }^{[26]}$ Hence, SSEP monitoring has become a standard of care during a wide variety of procedures.

\section{Financial support and sponsorship} Nil.

\section{Conflicts of interest}

There are no conflicts of interest.

\section{REFERENCES}

1. Grundy BL. Monitoring of sensory evoked potentials during neurosurgical operations: Methods and applications. Neurosurgery 1982;11:556-75.

2. Sloan TB, Jameson L, Janik D. Evoked potentials. In: Cottrell JE, Young WL, editors. Cottrell and Young's Neuroanesthesia. $5^{\text {th }}$ 
ed. Philadelphia: Mosby, Elsevier; 2010. p. 115-30.

3. Liem L. Intraoperative Neurophysiological Monitoring; Medscape. Available from: http://www.emedicine.medscape. com/article/1137763-overview. [Last cited on 2015 Aug 02].

4. Kumar A, Bhattacharya A, Makhija N. Evoked potential monitoring in anaesthesia and analgesia. Anaesthesia 2000;55:225-41.

5. Guideline. Available from: https://www.acns.org/pdf/ guidelines/Guideline-11B.pdf. [Last cited on 2015 Aug 02].

6. Stecker MM. A review of intraoperative monitoring for spinal surgery. Surg Neurol Int 2012;3 Suppl 3:S174-87.

7. Nuwer MR, Dawson EG, Carlson LG, Kanim LE, Sherman JE. Somatosensory evoked potential spinal cord monitoring reduces neurologic deficits after scoliosis surgery: Results of a large multicenter survey. Electroencephalogr Clin Neurophysiol 1995;96:6-11.

8. Mahla ME, Black S, Cucchiara RF. Neurologic monitoring. In: Miller RD, editor. Miller's Anesthesia. $6^{\text {th }}$ ed., Vol. 1. Philadelphia: Elsevier, Churchill Livingstone. p. 1511-50.

9. Sloan T. Anesthesia and intraoperative neurophysiological monitoring in children. Childs Nerv Syst 2010;26:227-35.

10. Sloan TB, Heyer EJ. Anesthesia for intraoperative neurophysiologic monitoring of the spinal cord. J Clin Neurophysiol 2002;19:430-43.

11. Van Der Walt JJ, Thomas JM, Figaji AA. Intraoperative neurophysiological monitoring for the anaesthetist. Part 2: A review of anaesthesia and its implications for intraoperative neurophysiological monitoring. S Afr J Anesth Analg 2013;19:197-202.

12. Engler GL, Spielholz NJ, Bernhard WN, Danziger F, Merkin H, Wolff T. Somatosensory evoked potentials during Harrington instrumentation for scoliosis. J Bone Joint Surg Am 1978;60:528-32.

13. Spielholz NI, Benjamin MV, Engler GL, Ransohoff J. Somatosensory evoked potentials during decompression and stabilization of the spine. Methods and findings. Spine (Phila Pa 1976) 1979;4:500-5.

14. Lueders H, Hahn J, Gurd A, Tsuji S, Dinner D, Lesser R, et al. Surgical monitoring of spinal cord function: Cauda equina stimulation technique. Neurosurgery 1982;11:482-5.

15. Novak K, Oberndorfer S. Electrophysiology and intraoperative neurophysiological monitoring. In: Grisold W, Soffietti R, editors. Handbook of Clinical Neurology. $3^{\text {rd }}$ Series. Vol. 104. Elsevier; 2012.
16. Min KT, Kim JH, Shin YS, Kwon SY, Nam YT. The monitoring of somatosensory evoked potentials and neurologic complications in aneurysm surgery. Yonsei Med J 2001;42:227-32.

17. Allen A, Starr A, Nudleman K. Assessment of sensory function in the operating room utilizing cerebral evoked potentials: A study of fifty-six surgically anesthetized patients. Clin Neurosurg 1981;28:457-81.

18. Markand ON, Dilley RS, Moorthy SS, Warren C Jr. Monitoring of somatosensory evoked responses during carotid endarterectomy. Arch Neurol 1984;41:375-8.

19. Keyhani K, Miller CC $3^{\text {rd }}$, Estrera AL, Wegryn T, Sheinbaum R, Safi HJ.Analysis of motor and somatosensory evoked potentials during thoracic and thoracoabdominal aortic aneurysm repair. J Vasc Surg 2009;49:36-41.

20. Landi A, Copeland SA, Parry CB, Jones SJ. The role of somatosensory evoked potentials and nerve conduction studies in the surgical management of brachial plexus injuries. J Bone Joint Surg Br 1980;62-B: 492-6.

21. Jellish WS, Sherazee G, Patel J, Cunanan R, Steele J, Garibashvilli K, et al. Somatosensory evoked potentials help prevent positioning-related brachial plexus injury during skull base surgery. Otolaryngol Head Neck Surg 2013;149:168-73.

22. Kumar A, Tandon OP, Bhattacharya A, Gupta RK, Dhar D. Somatosensory evoked potential changes following electro-acupuncture therapy in chronic pain patients. Anaesthesia 1995;50:411-4.

23. Amantini A, Carrai R, Lori S, Peris A, Amadori A, Pinto F, et al. Neurophysiological monitoring in adult and pediatric intensive care. Minerva Anestesiol 2012;78:1067-75.

24. Manninen PH, Patterson S, Lam AM, Gelb AW, Nantau WE. Evoked potential monitoring during posterior fossa aneurysm surgery: A comparison of two modalities. Can J Anaesth 1994;41:92-7.

25. Lam AM, Manninen PH, Ferguson GG, Nantau W. Monitoring electrophysiologic function during carotid endarterectomy: A comparison of somatosensory evoked potentials and conventional electroencephalogram. Anesthesiology 1991; 75:15-21.

26. Neuromonitoring Information Statement. Scoliosis Research Society. Available from: https://www.srs. org/about-srs/quality-and-safety/position-statements/ neuromonitoring-information-statement. [Last cited on 2015 Aug 02]. 